\title{
Outcomes after Radiation Therapy for HIV Positive Patients with Invasive Cervical Cancer
}

\author{
Victoire Molinier ${ }^{1}$, Florence Huguet ${ }^{2}$, Marcos Ballester ${ }^{2}$, Marina Karmochkine ${ }^{3}$, Christophe Hennequin ${ }^{4}$, \\ Jean-Jacques Mazeron ${ }^{5} \&$ Catherine Durdux ${ }^{1}$ \\ ${ }^{1}$ Department of Radiation Oncology, Européen Georges Pompidou Hospital, Hôpitaux Universitaires Paris Ouest, \\ Assistance Publique Hôpitaux de Paris (APHP), University Paris V René Descartes, Paris, France \\ ${ }^{2}$ Department of Radiation Oncology, Tenon Hospital, Hôpitaux Universitaires Paris Est, APHP, University Paris \\ VI Pierre et Marie Curie, Paris, France \\ ${ }^{3}$ Department of Immunology, Européen Georges Pompidou Hospital, Hôpitaux Universitaires Paris Ouest, APHP, \\ University Paris V René Descartes, Paris, France \\ ${ }^{4}$ Department of Radiation Oncology, Saint-Louis Hospital, Hôpitaux Universitaires Paris, APHP, University \\ Paris VII Diderot, Paris, France \\ ${ }^{5}$ Department of Radiation Oncology, Pitié-Salpétrière Hospital, Hôpitaux Universitaires Paris Est, APHP, \\ University Paris VI Pierre et Marie Curie, Paris, France
}

Received: November 14, $2017 \quad$ Accepted: December 1, $2017 \quad$ Online Published: January 6, 2018

doi:10.5539/cco.v7n1p12 URL: https://doi.org/10.5539/cco.v7n1p12

\begin{abstract}
Objective: To assess tolerance, local control, and survival outcomes for HIV (human immunodeficiency virus) positive patients with locally advanced cervical cancer (CC) treated with external beam radiation therapy (EBRT) and/or brachytherapy from an Assistance Publique - Hôpitaux de Paris (APHP) retrospective cohort.
\end{abstract}

Methods: Between 2000 and 2014, 28 HIV positive patients presenting with a non-metastatic CC were treated in one of the five APHP radiation therapy centers. Fifteen patients (54\%) underwent primary surgery. Twenty-four patients (88\%) received EBRT, with concurrent chemotherapy in 22 cases, and $68 \%$ received brachytherapy.

Results: The median follow-up was 58 months. At 5 years, local control (LCR) and overall survival rates (OS) were $56 \%$ and $46.5 \%$ respectively. A grade 3-4 acute toxicity (mainly hematological toxicity) was reported in 18 patients $(64 \%)$. In univariate analysis, total irradiation dose $(\mathrm{p}=0.03)$ and cisplatin-based chemotherapy $(\mathrm{p}=0.005)$ were predictive of acute toxicity. A grade 3-4 late toxicity (mainly gastro-intestinal and renal) was observed in 7 patients (25\%). In univariate analysis, HIV stage at diagnosis $(\mathrm{p}=0.02)$ and an initial CD4 count <200/mm3 $(\mathrm{p}=0.03)$ were predictive factors of late toxicity.

Conclusion: In this study including HIV positive patients with $\mathrm{CC}$, local control and overall survival rates seemed to be lower than those reported in the literature for non-HIV patients. We also reported an increase in acute and late toxicity, mainly hematological, underlying the fundamental role of immunosuppression in tolerance to radiation therapy.

Keywords: AIDS, HIV, cervical cancer, radiation therapy

\section{Introduction}

Cervical cancer (CC) is the second most common cancer in women worldwide with a global annual incidence of 528000 new cases. With an estimated mortality of 266000 deaths each year, CC remains one of the leading causes of cancer and cancer mortality among women in the developing world, including women infected concurrently with human papilloma virus (HPV) and human immunodeficiency virus (HIV) (Ferlay et al., 2015, Awolude, Morhason-Bello, Denny \& Adewole, 2013). In France, in 2014, there were an estimated 3028 new cases and 1102 deaths due to CC (Bulletin épidémiologique hebdomadaire, 2014). HIV-infected women are more likely than uninfected women to develop cervical HPV infections and to progress through preneoplastic stages to CC (Chaturvedi, Madeleine, Biggar \& Engels, 2009). HIV-infected women with a CD4 cell counts lower than 200/mm3 are eight times more likely to develop CC (Abraham et al., 2013). Highly effective anti-retroviral therapy (HAART) increases overall survival (OS) among HIV-infected women but does not 
prevent them from developing CC. Since 1999, several studies have reported that chemoradiation therapy (CRT) was superior to radiation alone (Keys et al., 1999, Whitney et al., 1999). In 2002, a meta-analysis confirmed that CRT with weekly cisplatin was associated with $6 \%$ improved survival for patients with locally-advanced CC. CRT is now the standard of care for IB2-IVA stages CC. However, CRT is associated with an increased hematological and gastrointestinal acute toxicity. In HIV-patients, chemoradiation is a challenge for the oncologist and the immunologist: to cure malignancy, to minimize treatment toxicity and to control HIV-related opportunistic infections. HIV-infected women treated with CRT may be at increased risk for infectious morbidity due to immunosuppression and drug interactions between HAART and chemotherapy. There is not much data available about outcomes and toxicity of CC in HIV-infected patients, so this retrospective study aims to assess tolerance, local control, and survival outcomes in HIV-infected patients with invasive CC treated by external beam radiation therapy (EBRT) and/or brachytherapy in an Assistance Publique - Hôpitaux de Paris (APHP) retrospective cohort.

\section{Materials and Methods}

\subsection{Patient's Records}

Between January 2000 and December 2014, 28 HIV-infected patients with CC treated by EBRT and/or brachytherapy in one of the five radiation oncology departments of the APHP were evaluated. In situ carcinomas and IA FIGO stage were excluded from the study. We reviewed retrospectively patients' charts for demographic data, tumor location, tumor histology, tumor and nodal stage as detected by computed tomography (CT) or positron emission tomography-CT (PET-CT). Prior use of HAART and CD4 cell counts at the start of treatment were documented. Details of the treatment received by the patient, its response, acute and late toxicities, and complications of HIV were also studied. Disease staging was defined according to the 2009 International Federation of Gynecology and Obstetrics (FIGO) (National Comprehensive Cancer Network, 2012). The hospital's Institutional Review Board approved this study.

\subsection{Treatment Strategies}

The decision to perform para-aortic lymphadenectomy staging from stage FIGO IB2 was taken by multidisciplinary board depending on comorbidities of the patient and lymph node involvement on imaging assessment. In case of lymph node involvement on the PET-CT, lymphadenectomy staging was not indicated.

\subsubsection{Chemoradiation Therapy}

The decision of CRT was taken by multidisciplinary tumor board. Patients were treated with three-dimensional conformal EBRT (3D-EBRT) or intensity-modulated radiation therapy (IMRT). A planning CT scan was required to define target volumes. Pre therapeutic pelvic magnetic resonance imaging (MRI) and/or ${ }^{18}$ FDG PET-CT were fused with the planning-CT to determine the Gross Tumor Volume (GTV) ant the Clinical Target Volume (CTV). The target volumes and organs at risk were defined according to the ICRU 50 or 83 Report (Chavaudra \& Bridier, 2001, Hodapp, 2012). Customized blocks or multileaf settings were used to minimize the radiation dose to the normal tissues. The prescription dose to the Planning Target Volume (PTV) was 44-51 Gy in 22-28 fractions of EBRT to the pelvis. EBRT was given in 1.8 to 2 Gy per fraction five days a week. A boost of 9-16 Gy was given on involved pelvic lymph nodes and/or parametrium. If brachytherapy was not feasible, a boost of 9-20 Gy was delivered on cervical tumor. If involved, the para-aortic nodes (PAN) field received 45 Gy in 1.8 Gy per fraction after the pelvic radiation therapy (RT). Hypofractionated regimen could be discussed.

If renal function allowed, $40 \mathrm{mg} / \mathrm{m}^{2}$ cisplatin was given weekly. If calculated glomerular filtration rate (GFR) was $<50 \mathrm{~mL} / \mathrm{min}$, weekly carboplatin area under the curve (AUC) 2 was used.

\subsubsection{Brachytherapy}

Depending on the availability in each center, low-dose rate (LDR) or high-dose rate (HDR) brachytherapy was planned after EBRT according to the dose recommendations (Lee et al., 2012, Viswanathan \& Thomadsen 2012, Viswanathan et al., 2012). The total doses of EBRT, LDR or HDR were calculated using the Equivalence software developed by the GEC-ESTRO with the Embrace protocol (EMBRACE). Overall treatment time recommended was 56 days or less (Krebs, Maillard, Gaillot-Petit, Ortholan \& Nguyen, 2015, Perez, Grigsby, Castro-Vita, \&Lockett, 1995, Fyles, Keane, Barton \& Simm, 1992).

\subsection{Assessment of Safety and Efficacy}

Reasons for not completing radiation and/or chemotherapy were noted, when available. Acute toxicity was assessed by weekly examination during treatment.

Follow-up was assessed by clinical examination every three months during the two first years, then every six 
months during three years and then yearly. Response data were collected at time of examination for brachytherapy planning and on clinical and examination MRI at six to eight weeks following the end of treatment.

\subsection{Statistical Analysis}

The statistical significance of differences in demographic factors, and clinical parameters was evaluated by means and standard deviations. Chi2 or Fisher's exact tests, when suitable, were used to compare the nonparametric and parametric qualitative data. Quantitative data were compared with Student's test. We decided to group tumor stages into three groups (staging groups): Group 1 for tumors located to the cervix (FIGO stage I), Group 2 for FIGO II and Group 3 for FIGO III and IVA.

Primary endpoint was local control rate (LCR). Secondary endpoints were overall survival (OS), acute, and late toxicities. Toxicity scoring was done using CTCAE v4.

Time to event endpoints including LCR, and OS were computed using the Kaplan-Meier method and compared using the log-rank test. In order to assess the precision of the obtained estimates, multivariable analysis with hazard ratios (HR) and 95\% CI were assessed from Cox proportional hazards models.

To identify risk factors of severe toxicity, multivariable logistic regression models were used. Results were expressed as odds ratios (OR) with $95 \%$ CI. Variables with $P$-values $\leq 0.2$ on univariate analysis were considered candidates for the multivariable analysis. Differences were assumed to be significant when $P<0.05$. Analyses were performed using XLSTAT® software version 2016.05.

\section{Results}

\subsection{Patient Characteristics (Table 1)}

From January 2000 through December 2014, 28 HIV-infected women with CC were treated by external beam radiation therapy (EBRT) and/or brachytherapy in APHP. Median age was 44 years old (range 24-60). Tumor characteristics are presented in Table 1. At diagnosis, 12 patients $(42 \%)$ had presented previous opportunistic infections. Twenty-four patients (86\%) were treated with an anti-retroviral therapy. Median CD4 cell count was $194 / \mathrm{mm}^{3}$ (range 31-876) with an undetectable viral load in $42 \%$ of patients. Eight patients had hepatitis B and/or $\mathrm{C}$ virus co-infection.

Table 1. Characteristics of patients.

\begin{tabular}{llllllll}
\hline Characteristics & Total & $\begin{array}{l}\text { Group 1 } \\
\text { FIGO IB1-IB2 }\end{array}$ & $\begin{array}{l}\text { Group 2 } \\
\text { FIGO II } \\
\end{array}$ & $\begin{array}{l}\text { Group 3 } \\
\text { N=11 }\end{array}$ & $\begin{array}{l}\text { FIGO IIIB-IVA } \\
\text { N=11 }\end{array}$ & N=6 & \\
\hline Mean age (years) & & $\mathrm{N}$ & $\%$ & $\mathrm{~N}$ & $\%$ & $\mathrm{~N}$ & $\%$ \\
Mean tumor size (mm) & & 39 & & 44 & & 44 & \\
\hline Pathological type & & 32.5 & & 46 & & 65 & \\
SCC & 24 & 10 & 35.7 & 8 & 28.6 & 6 & 21.4 \\
ADK & 3 & 1 & 3.6 & 2 & 7.1 & 0 & 0 \\
ASCC & 1 & 0 & 0 & 1 & 3.6 & 0 & 0 \\
\hline Embolism & & & & & & & \\
Yes & 7 & 4 & 14.2 & 2 & 7.2 & 1 & 3.6 \\
No & 9 & 2 & 7.2 & 6 & 21.5 & 1 & 3.6 \\
NE & 12 & 5 & 17.8 & 3 & 10.7 & 4 & 14.2 \\
\hline Concurrent chemotherapy & & & & & & & \\
Yes & 22 & 7 & 25 & 9 & 32.2 & 6 & 21.4 \\
No & 6 & 4 & 14.2 & 2 & 7.2 & 0 & 0 \\
\hline Imaging Nodal status & & & & & & & \\
N1 & 22 & 3 & 10.7 & 7 & 25 & 4 & 14.2 \\
N0 & 6 & 8 & 28.7 & 4 & 14.2 & 2 & 7.2 \\
\hline
\end{tabular}

Abbreviations: ADK, adenocarcinoma; ASCC, adenosquamous cell carcinoma; $\mathrm{N}$, number of patients; $\mathrm{NE}$, non evaluated; SCC, squamous cell carcinoma. 


\subsection{Treatment Outcomes}

\subsubsection{Chemoradiation}

Twenty-four patients (86\%) received 3D-EBRT. Only one patient was treated with IMRT. The median EqD2 dose given to the pelvis PTV was 45 Gy (range 24-52 Gy). Two patients received a hypofractionated RT. Eight patients received a boost on positive pelvic lymph nodes and/or parametrium with a median dose of $9.5 \mathrm{~Gy}$. A RT boost on the tumor was performed in four cases not suitable for brachytherapy, with a median dose of $16.7 \mathrm{~Gy}$. Two patients received PAN field irradiation due to lymph node involvement on the PET-CT. The median EqD2 dose given to the cervix tumor including centropelvic boost or brachytherapy was 59.7 Gy. Among patients treated with EBRT, 22 had concurrent RT but only four received the chemotherapy with full dose-intensity.

\subsubsection{Brachytherapy}

Nineteen patients (68\%) underwent brachytherapy with a median dose of $20 \mathrm{~Gy}$ and $10 \mathrm{~Gy}$ respectively for LDR and HDR. Mean overall treatment time for CRT plus brachytherapy was 71 days (range 43-193 days). Only five patients completed the treatment in 56 days or less. Nine patients (32\%) did not receive brachytherapy mainly due to delayed healing, necrosis, uterine perforation, or impossible mold application.

\subsection{Survival}

The median follow-up was 58 months (range 5-150 months). The 2-year LCR rate was $62 \%$ for the whole population (Figure 1). After completing EBRT and/or brachytherapy, 21 (75\%) patients achieved a complete response and seven $(25 \%)$ showed progressive disease or no response to treatment. In univariate analysis, staging group ( $\mathrm{p}=0.05)$, tumor size $(\mathrm{p}=0.05)$, and chemotherapy without cisplatin were predictive factor of incomplete response. None predictive factor of response has been identified in multivariable analysis. Five patients (18\%) presented a relapse (one local, two local and nodal, and two nodal and metastatic). In univariate analysis, nodal status ( $\mathrm{p}=0.041$ ) was the only predictive factor of relapse. None predictive factor of relapse has been identified in multivariable analysis.

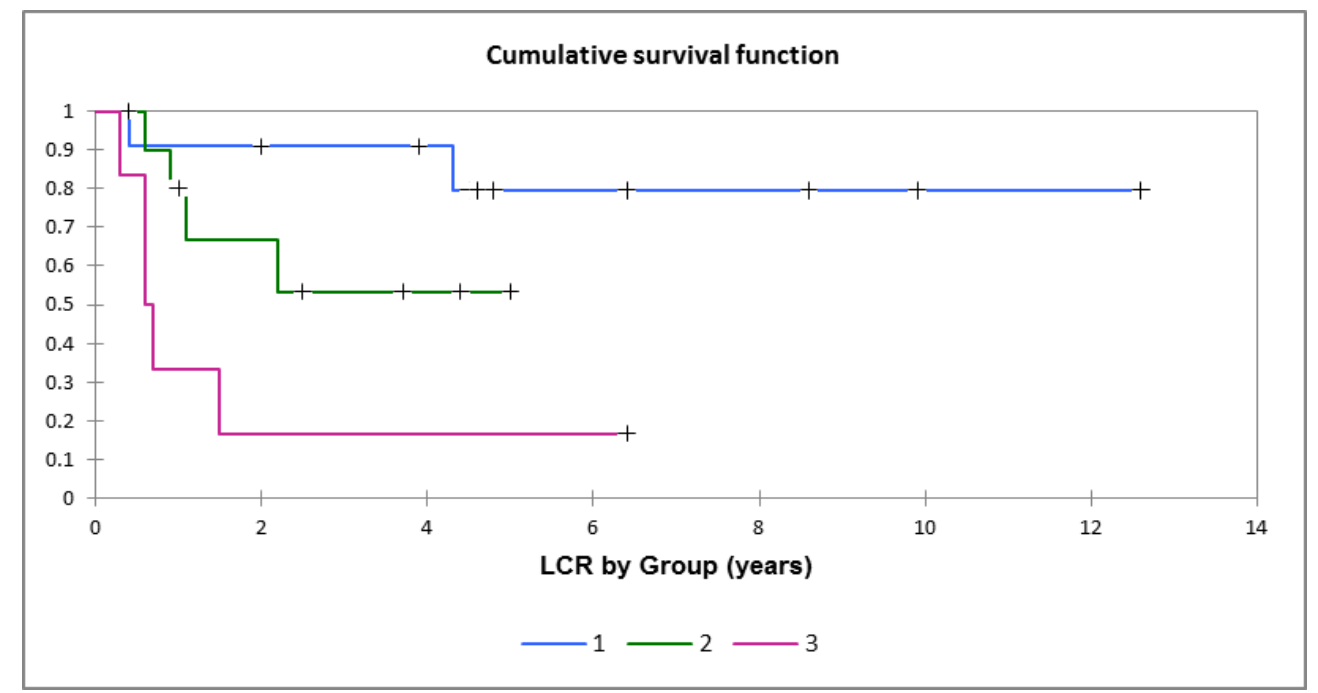

Figure 1. Local control rate (LCR) after stratification by Group. Group 1 for tumors located to the cervix (FIGO stage I), Group 2 for FIGO II and Group 3 for FIGO III and IVA. Patients at risk: Group 1 (11 patients); Group 2 (11 patients); Group 3 (6 patients)

\begin{tabular}{llll}
\hline Group & \multicolumn{3}{l}{ 5-year survival } \\
\hline & Total cases & Cases deceased (\%) & p-value \\
$\mathbf{1}$ & 11 & 18.2 & 0.007 \\
$\mathbf{2}$ & 11 & 54.5 & \\
$\mathbf{3}$ & 6 & 66.6 & \\
\hline
\end{tabular}

Staging group $(\mathrm{p}=0.04)$, nodal stage $(\mathrm{p}=0.01)$, irradiation dose $(\mathrm{p}=0.03)$, and overall time of EBRT $(\mathrm{p}=0.04)$ were predictive factor of worse LCR in univariate analysis. In multivariable analysis, nodal stage (HR=163.5; CI 95\% 3.5-7448.7; $\mathrm{p}=0.009$ ) was the only independent predictive factor of a decreased LCR. A trend of lower LCR was observed for Group 3 (HR=15.2; CI 95\% 0.9-258.3; $\mathrm{p}=0.059)$ but was not statistically significant. 
At the time of analysis, 13 patients died. The 2 and 5-year OS rate were $72.6 \%$ and $46.5 \%$ respectively. After stratification by staging group, the 2-year OS range from $100 \%$ (Group 1) to $25 \%$ (Group 3). None predictive factor of OS has been identified in multivariable analysis.

\subsection{Toxicity}

\subsubsection{Acute toxicity}

Eighteen patients (64.3\%), all treated by EBRT, presented at least one grade 3-4 acute toxicity, mainly hematological. Among these patients, 17 had received concurrent chemotherapy and 2 had PAN field radiation therapy. Nine $(32.1 \%)$ and fifteen $(53.6 \%)$ patients developed grade 3-4 leucopenia and lymphopenia, respectively. Lymphocyte and CD4 cell count dropped from $68.5 \%$ and $54.7 \%$, respectively. The different types of acute toxicity are presented in Table 2 . In univariate analysis, predictive factor of acute toxicity were age $(\mathrm{p}=0.03)$, EBRT $(\mathrm{p}=0.01)$, and irradiation dose $(\mathrm{p}=0.003)$. No death was related to toxicity.

Table 2. Acute toxicity

\begin{tabular}{ccccccccccccc}
\hline Grade & \multicolumn{10}{c}{ Acute toxicity by localization } \\
\hline & \multicolumn{1}{c}{ Skin } & \multicolumn{1}{c}{ GI } & \multicolumn{2}{c}{ Renal } & Urinary & \multicolumn{2}{l}{ White cells } & \multicolumn{2}{c}{ Lymphocytes } \\
\cline { 2 - 13 } & N & $\%$ & N & $\%$ & N & $\%$ & N & $\%$ & N & $\%$ & N & $\%$ \\
\hline G1-2 & 2 & 8 & 9 & 32 & 0 & 0 & 1 & 4 & 7 & 25 & 5 & 18 \\
G3-4 & 1 & 4 & 0 & 0 & 1 & 4 & 1 & 4 & 9 & 32 & 15 & 54 \\
NE & 0 & 0 & 0 & 0 & 0 & 0 & 0 & 0 & 1 & 4 & 4 & 14 \\
\hline
\end{tabular}

Abbreviations: G, grade; GI, gastrointestinal; N, number of patients; NE, not evaluated.

\subsubsection{Late Toxicity}

Seven patients (25\%) had at least one grade 3-4 renal and/or gastrointestinal (GI) late toxicities. No patient had grade 3-4 genitourinary toxicity. The different types of late toxicity are presented in Table 3. In univariate analysis, patients with a CD4 count cell $<200 / \mathrm{mm}^{3}$ were 17 times more likely to develop late toxicity $(\mathrm{OR}=17.2$; CI 95\% 1.5-196.3; $\mathrm{p}=0.031$ ). None predictive factor of late toxicity has been identified in multivariable analysis.

Table 3. Late toxicity

\begin{tabular}{ccccccccccc}
\hline Grade & \multicolumn{10}{c}{ Late toxicity by localization } \\
\hline & \multicolumn{1}{c}{ Skin } & \multicolumn{1}{c}{ GI } & \multicolumn{2}{c}{ Renal } & \multicolumn{3}{c}{ Urinary } & \multicolumn{2}{c}{ Lymphocytes } \\
\cline { 2 - 10 } & $\mathrm{N}$ & $\%$ & $\mathrm{~N}$ & $\%$ & $\mathrm{~N}$ & $\%$ & $\mathrm{~N}$ & $\%$ & $\mathrm{~N}$ & $\%$ \\
\hline G1-2 & 0 & 0 & 0 & 0 & 0 & 0 & 0 & 0 & 1 & 4 \\
G3-4 & 0 & 0 & 4 & 14 & 3 & 10 & 0 & 0 & 0 & 0 \\
NE & 2 & 8 & 2 & 8 & 2 & 8 & 2 & 8 & 9 & 32 \\
\hline
\end{tabular}

Abbreviations: G, grade; GI, gastrointestinal; N, number of patients; NE, not evaluated.

\subsection{HIV Complications}

Median lower CD4 cell count was $130 / \mathrm{mm}^{3}$ (range 5-251/ $\mathrm{mm}^{3}$ ) for the whole population and was mainly reported during the first three months after EBRT start. Five patients (17.9\%) presented at least one complication of HIV infection. Among these five patients, two had already developed opportunistic infections before initial diagnosis of CC. One patient presented a Burkitt's lymphoma 27 months after the end of treatment. Another patient presented an anal condylomatosis 53 months after the end of the treatment. Four other patients had infectious bacterial complications (two patients), viral (two patients), or fungal (one patient). Table 4 summarizes main characteristics of patients who had a complication of HIV infection after treatment of their CC. 
Table 4. HIV's complications after treatment of CC

\begin{tabular}{|c|c|c|c|c|c|c|c|c|}
\hline \multirow[t]{2}{*}{ Patient } & \multicolumn{4}{|c|}{ HIV's characteristics at diagnosis } & \multirow{2}{*}{$\begin{array}{c}\mathrm{CD} 4 \\
\text { rate } 3 \text { months after } \\
\text { treatment }\left(/ \mathrm{mm}^{3}\right)\end{array}$} & \multirow{2}{*}{$\begin{array}{c}\mathrm{CD} 4 \\
\text { rate } 1 \text { year after } \\
\text { treatment }\left(/ \mathrm{mm}^{3}\right) \\
\end{array}$} & \multicolumn{2}{|c|}{ Complications } \\
\hline & OI & $\begin{array}{l}\text { HIV } \\
\text { TTT }\end{array}$ & $\begin{array}{c}\mathrm{CD} 4 \\
\left(/ \mathrm{mm}^{3}\right)\end{array}$ & $\begin{array}{c}\mathrm{VL} \\
\text { (copies/mL) }\end{array}$ & & & OI type & $\begin{array}{c}\text { Delay } \\
\text { (months) }\end{array}$ \\
\hline Patient 1 & Yes & Yes & 292 & $<20$ & 40 & 185 & Cellulitis & 27 \\
\hline Patient 2 & No & Yes & 180 & $<20$ & 65 & 96 & $\begin{array}{l}\text { Anal condylomatosis, } \\
\text { vulvar-vaginitis }\end{array}$ & 52 \\
\hline Patient 3 & Yes & Yes & 180 & $4 \times 10^{5}$ & 87 & 107 & $\begin{array}{l}\text { Burkitt's medullary } \\
\text { lymphoma }\end{array}$ & 24 \\
\hline Patient 4 & No & Yes & 406 & $4 \times 10^{4}$ & 118 & 260 & Chronic genital herpes & 9 \\
\hline Patient 5 & No & Yes & 453 & $<20$ & 199 & 377 & $\begin{array}{l}\text { Sacral herpes, severe } \\
\text { sepsis }\end{array}$ & - \\
\hline
\end{tabular}

Abbreviations: HIV, human immunodeficiency virus; OI, opportunistic infection; TTT, treatment; VL, viral load.

\section{Discussion}

The literature regarding radiation therapy related toxicity in HIV-infected women with $\mathrm{CC}$ is poor. Our study assessed tolerance, local control, and survival outcomes for HIV-infected patients with invasive CC treated by EBRT and/or brachytherapy. Our median follow-up was longer than four years. Relapses usually happen during the first three years after completion of the EBRT. Our database contained few missing data, which allowed us to study many predictive parameters in univariate analysis. For uni and multivariate survival analyzes, the tumor stage was stratified into three groups according to tumor extensions independently of tumor size, a grouping already used in various publications (Rose et al., 2015, Herrera \& Prior, 2013). Thus, stages IB1 and IB2 are analyzed together in Group 1 although their management is usually different. In our study, main characteristics and the therapeutic management of IB1 and IB2 stages were found to be similar. This choice can still be criticized because of the difference in tumor size between the IB1 and the IB2 as well as the risk of lymph node involvement.

The main limit of this study is its retrospective nature. Moreover, the majority of patients included were not born in France (mainly from sub-Saharan Africa). Another limitation of our study is the low number of included patients. We studied 28 patients while the main series published included between 36 and 87 patients (Simonds, Wright, du Toit, Neugut \& Jacobson, 2012, Simonds, Neugut \& Jacobson, 2015, Ferreira et al., 2017, Shrivastava, Engineer, Rajadhyaksha \& Dinshaw, 2005) The four major studies have been carried out in developing countries where the incidence of CCU and HIV is higher than in France.

Demographic and oncologic characteristics seem different between HIV-infected and non-infected women. Patients with HIV positive status are 5-10 years younger in age (Gichangi et al, 2002, Lomalisa, Smith \& Guidozzi, 2000). In Shrivastava et al. (2005) series, median age of women with HIV-positive CC was 41 years compared to 48 for HIV-negative women.. It points toward the hypothesis that HIV infection shortens the latent period naturally observed in the progression of preneoplastic cervical lesions to CC. Moreover, in our study, lymph node involvement was more frequent, particularly in IB (IB1 22\%, IB2 33\%) and II (IIA 50\%, IIB 44\%), respectively, compared with $17 \%$ and $12-30 \%$ respectively in the general population of the literature confirming the severity of CC in HIV-infected population (Michel et al., 1998, Ayhan, Celik \& Dursun, 2008).

\subsection{Difficulties of Treatment and Loss of Chance}

In our HIV positive population, we found differences in management for locally advanced CC compared to therapeutic standards due to difficulties in performing brachytherapy or bad tolerance of treatment. For the CRT part, the median dose given to the pelvis was $45 \mathrm{~Gy}$, dose similar to those recommended (Simonds et al., 2012, Simonds et al., 2015, Ferreira et al., 2017, Shrivastava et al., 2005) but the median EqD2 dose received by the cervical tumor, taking into account brachytherapy or the centro-pelvic boost was only $59.7 \mathrm{~Gy}$. This dose is lower than the dose of 68 Gy considered adequate after CRT and brachytherapy (Simonds et al., 2012, Simonds et al., 2015). Brachytherapy, indicated in 18 cases (IB2 to IIIB), could not be performed in 9 patients (32.1\%) due to complication of CRT.

The mean overall treatment time for the CRT and brachytherapy was 72 days with very large deviations up to 27.5 weeks. However, a spread of more than 56 days is a pejorative prognostic factor for LCR and OS in several published studies (Krebs et al., 2015, Perez et al., 1995, Fyles et al., 1992, Chen, Liang, Yang, Ko \& Lin, 2003). Finally, among the 22 patients treated with CRT, a dose-intensity reduction in platinum dose was observed in 10 
of the 14 evaluable patients (missing data).

Shrivastava et al. (2005) described a retrospective cohort of 42 HIV positive patients treated at the Tata Memorial Hospital in India. Only 22 patients completed EBRT. Simonds et al. (2012) published a retrospective study of 461 patients treated in South Africa and 59 of whom were HIV-positive. Only $79 \%$ of HIV positive patients received a total dose of at least 68 Gy versus $90 \%$ of HIV negative patients $(\mathrm{p}=0.03)$. Only 53\% of HIV positive patients received at least four cycles of cisplatin versus $75 \%$ of HIV negative patients $(\mathrm{p}=0.01)$. Overall, $45 \%$ of HIV positive patients completed the recommended treatment versus $70 \%$ of HIV negative patients $(\mathrm{p}=0.001)$. These authors showed in a prospective study included 213 patients with $36 \mathrm{HIV}$-infected women that HIV population received more frequently EBRT alone (without chemotherapy) than the negative HIV population (39\% versus $24 \%, \mathrm{p}=0.01$ ) (Simonds et al. 2015).

\subsection{Survival}

Our LCR (61.6\% at 2 years) was lower compared to the Vienna series, including HIV negative patients, which was $97 \%$ for all stages, and in which very high doses eqD2 (D90 CTV HR> 90 Gy) were delivered with brachytherapy with a toxicity rate lower than 5\% (Pötter et al., 2007).

Gichangi et al. (2006) showed that $19 \%$ of the patients had residual tumor at 4 and 7 months after EBRT. For these authors, a treatment duration longer than 50 days multiplied the risk of poor response by five (HR=4.4; CI 95\% 1.8-13.3; $\mathrm{p}=0.001)$. In case of residual tumor, treatment was 10 days longer $(\mathrm{p}=0.001)$. Positive HIV status was associated with an HR of 3.7 (CI 95\% 1.3-10.2; $\mathrm{p}=0.009$ ) of residual tumor.

Dryden-Peterson et al. (2016) reported that 3-year survival for HIV positive patients was only $35 \%$ in Botswana, a rate lower to our 3-year OS rate, which could exceed 50\%. In a non-VIH population, Han, Milosevic, Fyles, Pintilie \& Viswanathan, (2013) showed that the 5-year OS rate was decreased in absence of brachytherapy (46\% versus 58\%), a rate similar to our 5-year OS. Ferreira et al. (2017) described a retrospective cohort of 87 HIV positive patients matched with 336 HIV negative patients on several criteria: age, year of CC diagnosis, FIGO stage, and histological type. In this study, among the 234 deaths, $9 \%$ of HIV positive patients died of their AIDS. HIV infection was associated with excess of mortality (HR=2.02; CI 95\% 1.27-3.22) and cancer specific mortality ( $\mathrm{RR}=4.35 \mathrm{IC} 95 \% 1.86-10.2)$ beyond the $1^{\text {st }}$ year following diagnosis.

\subsection{Toxicity}

In our study, grade $3-4$ acute toxicity was observed in $64.3 \%$. Grade 2 and 3 skin toxicity levels were $3.5 \%$ and $3.6 \%$, respectively, below the rate reported by Shrivastava et al. (2005) which was $72 \%$ and $27 \%$, respectively. These authors reported $14 \%$ grade 3-4 GI toxicity while it was zero in our series. Our rate of $\geq$ grade 2 genito-urinary toxicity was $7.2 \%$ versus $18 \%$ in the TATA Memorial series..Positive HIV status increased the risk of developing multiple toxicities simultaneously (cutaneous, GI, genitourinary) and was an independent risk factor for discontinuation of treatment ( $\mathrm{HR}=2.2$ IC 95\% 1.1-4.5), $\mathrm{p}=0.04)$ in the study published by Gichangi et al. (2006). We described $32 \%$ of grade 3-4 leucopenia, very similar to the results of the prospective study by Simonds et al. (2015) (31\% versus $10 \%$ in the HIV negative population $(\mathrm{p}=0.003)$ ). In this series, two factors were predictive of grade 3-4 toxicity: concurrent chemotherapy (OR=4.41 IC 95\% 1.76-11.1, p=0.023) and positive HIV status ( $\mathrm{OR}=2.16$ IC $95 \%(0.98-4.8), \mathrm{p}=0.05)$. No publication has assessed lymphocyte toxicity.

In our series, grade 3-4 late toxicity was $21.4 \%$, exclusively GI or renal.

We failed to find published data comparing late toxicity between HIV positive and negative population. In our study, an initial CD4 cell count $<200 / \mathrm{mm}^{3}$ increased the risk of developing late toxicity by 17 , highlighting the role of severe immunosuppression in radiotherapy tolerance. Over the period studied, only one patient was treated with IMRT. At that time, this technique was not recommended in France despite of favorable dosimetric data (Yang et al., 2012). In the intermediate analysis of TATA Memorial Phase III trial with IMRT, with a 20-month median follow-up, a decreased grade 3 late GI toxicity rate was reported in patients treated postoperatively ( $3.2 \%$ versus $17.6 \%$ for the $3 \mathrm{D}-\mathrm{RTC}$ arm, $\mathrm{p}=0.02)$ for uterine malignancies. The results of the final analysis will be available after a median follow-up of three years (Chopra et al., 2015). But it seems now essential to use IMRT in all patients, especially in HIV positive patients with significant immunosuppression.

\section{Conclusion}

This retrospective study was carried out from all the HIV patients treated by ionizing radiation at the APHP for a non-metastatic cervical infiltrating cancer. To our knowledge, this is the most important European series reported. It allowed us to study tolerance and outcomes of radiation therapy and/or brachytherapy in this special population. This study appears to show lower local control and overall survival than those reported in the literature for non-HIV patients. There was also an increase in toxicity, particularly hematological, confirming the 
fundamental role of immunosuppression in tolerance to radiation therapy. Nevertheless, in the context of a heterogeneous retrospective study with small numbers, these conclusions should be considered with caution.

\section{Acknowledgement}

The authors report no conflicts of interest.

\section{References}

Abraham, A., D’Souza, G., Jing, Y., Gange, S., Sterling, T., Silverberg, M., ... Strickler, HD. (2013). Invasive Cervical Cancer Risk Among HIV-Infected Women: A North American Multicohort Collaboration Prospective Study. JAIDS-J Acquir IMMUNE Defic Syndr, 62(4), 405-413. https://doi.org/10.1097/QAI.0b013e31828177d7

Awolude, OA., Morhason-Bello, IO., Denny, LA., \& Adewole, IF. (2013). Human papillomavirus infection and related cancers in sub-Saharan Africa: burden and tools for prevention. Vaccine, 31 Suppl 5.

Ayhan, A., Celik, H., \& Dursun, P. (2008). Lymphatic mapping and sentinel node biopsy in gynecological cancers: a critical review of the literature. World J Surg Oncol, 6, 53. https://doi.org/10.1186/1477-7819-6-53

Bulletin épidémiologique hebdomadaire (2014) - Le cancer du col de l'utérus : état des connaissances en 2014. Retrieved from http://www.invs.sante.fr/beh/2014/13-14-15/2014_13-14-15_1.html

Chaturvedi, A. K., Madeleine, M. M., Biggar, R. J., \& Engels, E. A. (2009). Risk of Human Papillomavirus-Associated Cancers Among Persons With AIDS. J Natl Cancer Inst, 101(16), 1120-1130. https://doi.org/10.1093/jnci/djp205

Chavaudra, J., \& Bridier, A. (2001). Definition of volumes in external radiotherapy: ICRU reports 50 and 62 . Cancer Radiothérapie, 5(5), 472-478. https://doi.org/10.1016/S1278-3218(01)00117-214.

Chen, S. W., Liang, J. A., Yang, S. N., Ko, H. L., \& Lin, F. J. (2003). The adverse effect of treatment prolongation in cervical cancer by high-dose-rate intracavitary brachytherapy. Radiother Oncol J Eur Soc Ther Radiol Oncol, 67(1), 69-76. https://doi.org/10.1016/S0167-8140(02)00439-5

Chopra, S., Engineer, R., Mahantshetty, U. M., Dora, T., Kannan, S., Phurailatpam, R., ... Shrivastava, S. K. (2015). Phase III RCT of Postoperative Adjuvant Conventional Radiation (3DCRT) Versus IGIMRT for Reducing Late Bowel Toxicity in Cervical Cancer (PARCER) (NCT01279135/CTRI2012/120349): Results of Interim Analyses. Int J Radiat Oncol Biol Phys, 93(3), S4.

Dryden-Peterson, S., Bvochora-Nsingo, M., Suneja, G., Efstathiou, JA., Grover, S., Chiyapo, S., ... Lockman, S. (2016) HIV Infection and Survival Among Women With Cervical Cancer. J Clin Oncol off J Am Soc Clin Oncol, https://doi.org/10.1200/JCO.2016.67.9613

EMBRACE: An intErnational study on MRI-guided BRachytherapy in locally Advanced CErvical cancer. Retrieved from https://www.embracestudy.dk/

Ferlay, J., Soerjomataram, I., Dikshit, R., Eser, S., Mathers, C., Rebelo, M., ... Bray, F. (2015). Cancer incidence and mortality worldwide: sources, methods and major patterns in GLOBOCAN 2012. Int J Cancer, 136(5), E359-386. https://doi.org/10.1002/ijc.29210

Ferreira, M. P., Coghill, A. E., Chaves, C. B., Bergmann, A., Thuler, L. C., Soares, E. A., ... Soares, M. A. (2017). Outcomes of cervical cancer among HIV-infected and HIV-uninfected women treated at the Brazilian National Institute of Cancer. AIDS Lond Engl, 31(4), 523-531. https://doi.org/10.1097/QAD.0000000000001367

Fyles, A., Keane, T. J., Barton, M., \& Simm, J. (1992). The effect of treatment duration in the local control of cervix cancer. Radiother Oncol J Eur Soc Ther Radiol Oncol, 25(4), 273-279. https://doi.org/10.1016/0167-8140(92)90247-R

Gichangi, P., De Vuyst, H., Estambale, B., Rogo, K., Bwayo, J., \& Temmerman, M. (2002). HIV and cervical cancer in Kenya. Int J Gynaecol Obstet Off Organ Int Fed Gynaecol Obstet, 76(1), 55-63. https://doi.org/10.1016/S0020-7292(01)00560-4

Gichangi, P., Bwayo, J., Estambale, B., Rogo, K., Njuguna, E., Ojwang, S., \& Temmerman, M. (2006). HIV impact on acute morbidity and pelvic tumor control following radiotherapy for cervical cancer. Gynecol Oncol, 100(2), 405-411. https://doi.org/10.1016/j.ygyno.2005.10.006

Han, K., Milosevic, M., Fyles, A., Pintilie, M., \& Viswanathan, AN. (2013). Trends in the utilization of 
brachytherapy in cervical cancer in the United States. Int J Radiat Oncol Biol Phys, 87(1), 111-119. https://doi.org/10.1016/j.ijrobp.2013.05.033

Herrera, FG., \& Prior, JO. (2013). The role of PET/CT in cervical cancer. Front Oncol, 3, 34. https://doi.org/10.3389/fonc.2013.00034

Hodapp, N. (2012). The ICRU Report 83: prescribing, recording and reporting photon-beam intensity-modulated radiation therapy (IMRT). Strahlenther Onkol Organ Dtsch Röntgenges Al, 188(1), 97-99. https://doi.org/10.1007/s00066-011-0015-x

Keys, HM., Bundy, BN., Stehman, FB., Muderspach, LI., Chafe, WE., Suggs, CL., ... Gersell, D. (1999). Cisplatin, radiation, and adjuvant hysterectomy compared with radiation and adjuvant hysterectomy for bulky stage IB cervical carcinoma. $N$ Engl J Med, 340(15), 1154-1161.

https://doi.org/10.1056/NEJM199904153401503

Krebs, L., Maillard, S., Gaillot-Petit, N., Ortholan, C., \& Nguyen, TD. (2015). Total radiation dose and overall treatment time are predictive for tumor sterilization in cervical carcinoma treated with chemoradiation and pulsed-dose-rate brachytherapy. Brachytherapy, 14(1), 16-22. https://doi.org/10.1016/j.brachy.2014.08.051

Lee, LJ., Das, IJ., Higgins, SA., Jhingran, A., Small, W., Thomadsen, B., ... Eifel, P. (2012). American Brachytherapy Society consensus guidelines for locally advanced carcinoma of the cervix. Part III: low-dose-rate and pulsed-dose-rate brachytherapy. Brachytherapy, 11(1), 53-57. https://doi.org/10.1016/j.brachy.2011.07.001

Lomalisa, P., Smith, T., \& Guidozzi, F. (2000). Human immunodeficiency virus infection and invasive cervical cancer in South Africa. Gynecol Oncol, 77(3), 460-463. https://doi.org/10.1006/gyno.2000.5775

Michel, G., Morice, P., Castaigne, D., Leblanc, M., Rey, A., \& Duvillard, P. (1998). Lymphatic spread in stage Ib and II cervical carcinoma: anatomy and surgical implications. Obstet Gynecol, 91(3), 360-363. https://doi.org/10.1016/S0029-7844(97)00696-0

National Comprehensive Cancer Network: Cervical cancer 2012. Retrieved from https://www.nccn.org/store/login/login.aspx

Perez, C. A., Grigsby, P. W., Castro-Vita, H., \& Lockett, M. A. (1995). Carcinoma of the uterine cervix. Impact of prolongation of overall treatment time and timing of brachytherapy on outcome of radiation therapy. Int $J$ Radiat Oncol Biol Phys, 32(5), 1275-1288. https://doi.org/10.1016/0360-3016(95)00220-S

Rose, P. G., Java, J., Whitney, C. W., Stehman, F. B., Lanciano, R., Thomas, G. M., ... DiSilvestro, P. A. (2015). Nomograms Predicting Progression-Free Survival, Overall Survival, and Pelvic Recurrence in Locally Advanced Cervical Cancer Developed From an Analysis of Identifiable Prognostic Factors in Patients From NRG Oncology/Gynecologic Oncology Group Randomized Trials of Chemoradiotherapy. J Clin Oncol Off J Am Soc Clin Oncol, 33(19), 2136-2142. https://doi.org/10.1200/JCO.2014.57.7122

Pötter, R., Dimopoulos, J., Georg, P., Lang, S., Waldhäusl, C., Wachter-Gerstner, N., ... Kirisits, C. (2007). Clinical impact of MRI assisted dose volume adaptation and dose escalation in brachytherapy of locally advanced cervix cancer. Radiother Oncol J Eur Soc Ther Radiol Oncol, 83(2), 148-155. https://doi.org/10.1016/j.radonc.2007.04.012

Shrivastava, S. K., Engineer, R., Rajadhyaksha, S., \& Dinshaw, K. A. (2005). HIV infection and invasive cervical cancers, treatment with radiation therapy: toxicity and outcome. Radiother Oncol J Eur Soc Ther Radiol Oncol, 74(1), 31-35. https://doi.org/10.1016/j.radonc.2004.11.006

Simonds, H. M., Wright, J. D., du Toit, N., Neugut, A. I., \& Jacobson, J. S. (2012). Completion of and early response to chemoradiation among human immunodeficiency virus (HIV)-positive and HIV-negative patients with locally advanced cervical carcinoma in South Africa. Cancer, 118(11), 2971-2979. https://doi.org/10.1002/cncr.26639

Simonds, H. M., Neugut, A. I., \& Jacobson, J. S. (2015). HIV Status and Acute Hematologic Toxicity Among Patients With Cervix Cancer Undergoing Radical Chemoradiation. Int J Gynecol Cancer Off J Int Gynecol Cancer Soc, 25(5), 884-890.

Viswanathan, A. N., \& Thomadsen, B. (2012). American Brachytherapy Society Cervical Cancer Recommendations Committee, American Brachytherapy Society. American Brachytherapy Society consensus guidelines for locally advanced carcinoma of the cervix. Part I: general principles. Brachytherapy, 11(1), 33-46. https://doi.org/10.1016/j.brachy.2011.07.003 
Viswanathan, A. N., Beriwal, S., De Los Santos, J., Demanes, D. J., Gaffney, D., Hansen, J., ... Erickson, B. (2012). The American Brachytherapy Society Treatment Recommendations for Locally Advanced Carcinoma of the Cervix Part II: High Dose-Rate Brachytherapy. Brachytherapy, 11(1), 47-52. https://doi.org/10.1016/j.brachy.2011.07.002

Yang, B., Zhu, L., Cheng, H., Li, Q., Zhang, Y., \& Zhao, Y. (2012). Dosimetric comparison of intensity modulated radiotherapy and three-dimensional conformal radiotherapy in patients with gynecologic malignancies: a systematic review and meta-analysis. Radiat Oncol Lond Engl, 7, 197. https://doi.org/10.1186/1748-717X-7-197

Whitney, C. W., Sause, W., Bundy, B. N., Malfetano, J. H., Hannigan, E. V., Fowler, W. C., ... Liao, S. Y. (1999). Randomized comparison of fluorouracil plus cisplatin versus hydroxyurea as an adjunct to radiation therapy in stage IIB-IVA carcinoma of the cervix with negative para-aortic lymph nodes: a Gynecologic Oncology Group and Southwest Oncology Group study. J Clin Oncol Off J Am Soc Clin Oncol, 17(5), 1339-1348. https://doi.org/10.1200/JCO.1999.17.5.1339

\section{Copyrights}

Copyright for this article is retained by the author(s), with first publication rights granted to the journal.

This is an open-access article distributed under the terms and conditions of the Creative Commons Attribution license (http://creativecommons.org/licenses/by/4.0/). 